Original Article

\title{
Evaluation of post-stroke functionality based on the International Classification of Functioning, Disability, and Health: a proposal for use of assessment tools
}

\author{
Soraia Micaela Silva, MSc, PT ${ }^{1)^{*}}$, Fernanda Ishida Corrêa, PhD, $\mathrm{PT}^{1}$, \\ Christina Danielli Coelho de Morais Faria, PhD, PT ${ }^{2}$, Cássia Maria Buchalla, PhD, MD ${ }^{3}$, \\ Paula Fernanda da Costa Silva, MSc, PT ${ }^{1)}$, João Carlos Ferrari Corrêa, PhD, PT $^{1)}$ \\ 1) Postgraduate Program in Rehabilitation Sciences, University Nove de Julho (UNINOVE): Rua \\ Vergueiro, 235/249 Liberdade, São Paulo, SP, CEP: 01504-001, Brazil \\ 2) Postgraduate Program in Rehabilitation Sciences, Federal University of Minas Gerais (UFMG), \\ Brazil \\ 3) Postgraduate Program in Public Health, University of São Paulo (USP), Brazil
}

\begin{abstract}
Purpose] This study aimed to identify the International Classification of Functioning, Disability, and Health categories addressed by the assessment tools commonly used in post-stroke rehabilitation and characterize patients based on its evaluation model. [Subjects and Methods] An exploratory, descriptive, cross-sectional study was conducted involving 35 individuals with chronic post-stroke hemiparesis. Handgrip strength was assessed to evaluate body functions and structures. The 10-meter gait speed test and Timed Up and Go test were administered to evaluate activity. The Stroke Specific Quality of Life scale was used to evaluate participation. Moreover, a systematic review of the literature was performed to identify studies that have associated these assessment tools with the International Classification of Functioning, Disability, and Health categories. [Results] The tools employed in this study for evaluating function addressed 63 International Classification of Functioning, Disability, and Health categories: 24 related to body functions and structures; 36 related to activity and participation; and 3 related to environmental factors. [Conclusion] The assessment tools employed in this study addressed 63 International Classification of Functioning, Disability, and Health categories and allowed a more complete evaluation of stroke survivors with hemiparesis. Use of this classification can therefore be more easily incorporated into clinical practice. Key words: Stroke, International Classification of Functionality, Disability, and Health, Physical therapy
\end{abstract}

(This article was submitted Jan. 7, 2015, and was accepted Feb. 7, 2015)

\section{INTRODUCTION}

The incidence and prevalence rates of cerebrovascular accident (stroke) have been reported to be high ${ }^{1,2)}$, and approximately $90 \%$ of stroke survivors have some type of disability $^{3)}$. In a study on the burden of diseases, stroke was found to be the third major cause of the loss of disabilityadjusted life years among 291 adverse health conditions worldwide ${ }^{4}$. Therefore, stroke was one of the first conditions to pique the interest of research groups that sought to study functionality based on the framework proposed in the International Classification of Functioning, Disability, and Health $(\mathrm{ICF})^{5,6)}$

The ICF model is based on the biopsychosocial approach

*Corresponding author. Soraia Micaela Silva (E-mail: soraia. micaelaa@gmail.com)

(C2015 The Society of Physical Therapy Science. Published by IPEC Inc. This is an open-access article distributed under the terms of the Creative Commons Attribution Non-Commercial No Derivatives (by-ncnd) License $<$ http://creativecommons.org/licenses/by-nc-nd/3.0/> . used to integrate the biological, individual, and social dimensions of health. Thus, functionality has become a broad term that includes interaction of positive aspects among the 3 main ICF components: 1) body functions and structures; 2) activity and participation; and 3) environmental and personal factors. With this model, the environment is seen as either a facilitator of or a barrier to functional recovery ${ }^{7}$.

Few studies have explored functionality based on the ICF conceptual model. In 2004, Geyh et al. ${ }^{8)}$ analyzed how individuals with hemiparesis stemming from a stroke were evaluated by researchers through a systematic review of 160 randomized, controlled, clinical trials involving stroke survivors. The authors found that $48 \%$ of the studies only evaluated body functions, $1 \%$ evaluated body structures, $45 \%$ only evaluated activity and/or participation, and $7 \%$ evaluated environmental factors. These findings demonstrate that post-stroke functionality is not yet evaluated in a comprehensive fashion, as recommended by the ICF. Specifically addressing the physiotherapeutic evaluation, Thonnard and Penta ${ }^{9}$ performed a review of the literature to identify the assessment tools used by physical therapists to evaluate patients with 4 different adverse health conditions, including 
stroke, and found that the evaluations were restricted to the "body functions and structures" and "activity" components.

Therefore, it appears that individuals with hemiparesis stemming from a stroke are not evaluated in a complete fashion, since not all the ICF components are considered in the evaluation process, as recommended by the World Health Organization. Thus, the present study aimed to identify ICF categories in assessment tools commonly used in poststroke rehabilitation and characterize patient functionality based on the ICF evaluation model. This analysis will allow identification of circumstances that either favor or hinder the rehabilitation process.

\section{SUBJECTS AND METHODS}

An exploratory, descriptive, cross-sectional study was conducted involving individuals with chronic hemiparesis stemming from a stroke, who were recruited from the physical therapy outpatient clinic of University Nove de Julho (São Paulo, Brazil). The inclusion criteria were: a clinical diagnosis of primary or recurrent stroke more than six months earlier, weakness and/or spasticity in the affected half of the body, and the ability to walk for at least 15 minutes with or without a gait-assistance device except a walker. The exclusion criteria were: presence of another clinical condition besides hemiparesis stemming from a stroke, motor aphasia, cognitive aphasia, and cognitive impairment (screened using the Mini Mental State Examination, with the cutoff points proposed by Bertolucci) ${ }^{10)}$.

The participants received clarifications regarding the objectives and procedures and were informed of the possibility of withdrawing from the study at any time with no negative consequences. All those who agreed to participate signed a statement of informed consent. This study was approved by the Human Research Ethics Committee of University Nove de Julho (São Paulo, Brazil) under process number 313776/13.

The evaluation protocol for the present investigation was based on 3 studies published in 2005. Salter et al. ${ }^{11-13)}$ indicated the most adequate assessment tools for the evaluation of individuals with chronic hemiparesis stemming from a stroke based on the ICF model. Barak and Duncan ${ }^{5)}$ published a similar study one year later. For inclusion, the test or measure needed to have previously been translated and cross-culturally adapted for use in Brazil (questionnaires), have adequate measurement properties (validity and reliability), and have easy clinical applicability.

Grip strength was assessed to evaluate body functions and structures, as this test is considered a predictor of overall muscle strength and functional capacity ${ }^{14)}$ and is easy to measure. The 10-meter gait speed test and Timed Up and Go test (TUGT) were used to evaluate activity, as these tests are simple, objective measures with easy clinical applicability and are good indicators of functional capacity in individuals with chronic hemiparesis ${ }^{15,16)}$. The Stroke Specific Quality of Life (SS-QOL) questionnaire was used to evaluate participation. According to Geyh et al. ${ }^{17)}$, health-related quality of life (HRQoL) and social participation are patient-oriented constructs. Thus, of all assessment tools, the HRQoL tools are the most indicated for evaluation of participation among stroke survivors ${ }^{5,11,18)}$.

Grip strength of both upper limbs was measured using a dynamometer (Jamar ${ }^{\circledR}$ Enterprises Inc., Irvington, New York, USA), with the grip handle in the second position. The volunteer remained seated in a chair without arm rests, with the shoulder in adduction and neutral rotation, elbow flexed at $90^{\circ}$, forearm in the neutral position, and wrist in slight extension $\left(0^{\circ}-30^{\circ}\right)^{19,20)}$. Three readings were taken on each side with a 20 -second rest period between readings, and means were calculated ${ }^{19,20)}$.

The 10-meter gait speed test was administered following the protocol proposed by Flansbjer et al. ${ }^{15}$ ), and gait velocity $(\mathrm{m} / \mathrm{s})$ was determined. The use of a brace or gait-assistance device was permitted, if necessary. The test was performed 3 times, and the mean was calculated ${ }^{15}$. The TUGT consists of standing up from a chair, walking 3 meters, turning around, returning to the chair, and sitting down again. The protocol proposed by Podsiadlo et al. ${ }^{21)}$ was used in the present study. The test was performed 3 times using a digital stopwatch ${ }^{22)}$, and the mean time to complete the task was calculated.

The preliminary measurement properties of the SS-QOL scale for the assessment of participation in stroke survivors were evaluated by Silva et al. ${ }^{23)}$, who concluded that the questionnaire was adequate and clinically useful. Moreover, the SS-QOL questionnaire is considered the most complete HRQoL assessment tool for evaluation of the ICF participation component, as it addresses a greater number of categories that involve participation in comparison to a generic HRQoL assessment tool ${ }^{24}$. The SS-QOL questionnaire has 12 domains (energy, family roles, language, mobility, mood, personality, self-care, social roles, thinking, upper extremity function, vision, and work/productivity), totaling 49 items. Each item has 5 response options scored from 1 to 5 points. The minimum total score is 49 (worst perception of quality of life), and the maximum is 245 (best perception of quality of life).

The evaluations were performed by a single examiner who had undergone theoretical and practical training in the use of the assessment tools. Due to the socio-cultural characteristics of the sample, the SS-QOL questionnaire was administered in interview form, as previously recommended in a study involving a Brazilian population ${ }^{25)}$, with the items always read in the same order.

For a systematic review of studies that have associated the assessment tools employed in the present study with ICF categories, searches were performed in the Medline, SciELO, and Lilacs databases. A search strategy was designed for each database using combinations of the following keywords: ("International Classification of Functioning, Disability, and Health" or ICF), ("handgrip strength"), (Timed "Up and Go" or TUGT"), ("10-meter gait speed or 10MGS"), ("Stroke Specific Quality of Life Scale" or SSQOL), and (comparison or link or linking). No restrictions were imposed regarding the language of the publication.

Studies were selected for full-text analysis using the following criteria: having been cited at least once in the aforementioned databases by July 2013, with no restriction imposed regarding the year of publication; and comparison and/or association between the concepts measured by the items of the assessment tool and the ICF components 
Table 1. Demographic and clinical characteristics of subjects

\begin{tabular}{lc}
\hline Variable & $(\mathrm{n}=35)$ \\
\hline Male & $19(54 \%)$ \\
Female & $16(46 \%)$ \\
Age (years) & $57.3 \pm 13.9$ \\
Time since stroke (years) & $4.1 \pm 3.5$ \\
Affected hemisphere & \\
Right & $13(37 \%)$ \\
Left & $22(63 \%)$ \\
Mini-Mental State Examination & $23(22 / 28)$ \\
\hline Data are expressed as absolute and relative fre- \\
quency; mean \pm SD for variables parametric; and \\
median and interquartile range $(25 \%$ and $75 \%)$ for \\
nonparametric variables.
\end{tabular}

and categories, following the methodological guidelines proposed by Cieza et al. ${ }^{26,27)}$. The selection of studies, data extraction, and analysis of the findings were performed by 2 independent examiners. In cases of disagreement, a third examiner was consulted, and a consensus was reached. For a comparison of different studies, the highest hierarchical level of the ICF cited in the selected studies was considered.

Descriptive analysis was used for characterization of the sample. The Shapiro-Wilk test was used to determine the distribution of the data (parametric or nonparametric). Central tendency and dispersion measures were used for quantitative variables. Frequencies were described for categorical variables. Nonparametric variables were expressed as medians and inter-quartile ranges.

\section{RESULTS}

Fifty-six individuals with chronic hemiparesis were recruited; of these, 9 were excluded for aphasia, 8 for scoring below the cutoff point on the Mini Mental State Examination, and 4 for having another disease associated with stroke. Thus, the final sample was comprised of 35 individuals. Table 1 displays the clinical and demographic characteristics of the sample.

Table 2 displays the descriptive statistics of the main outcome variables of the 3 ICF components. Parametric distribution was found for grip strength, gait speed, and functional mobility (TUGT). Nonparametric distribution was found for HRQoL analyzed using the SS-QOL questionnaire.

In the systematic review of the literature, 4 studies met the eligibility criteria and were selected for analysis ${ }^{17,} 18,28,29$. Table 3 displays the ICF categories considered by the assessment tools employed in the present study. A total of 63 ICF categories were identified: 24 related to body functions and structures; 36 related to activity and participation; and 3 related to environmental factors.

\section{DISCUSSION}

Considering the need to know the functional consequences stemming from a stroke and the repercussions with regard
Table 2. Central tendency values and dispersion of the variables associated with the ICF components

\begin{tabular}{lc}
\hline Measurement/Score & $(\mathrm{n}=35)$ \\
\hline Body functions and structures component & \\
HSp $(\mathrm{kg})$ & $11.8 \pm 8.8$ \\
HSnp $(\mathrm{kg})$ & $30.2 \pm 10.0$ \\
Activity Component & \\
Natural GS (m/s) & $1.0 \pm 0.8$ \\
Maximal GS (m/s) & $1.3 \pm 1.1$ \\
TUGT (s) & $16.4 \pm 7.4$ \\
Participation Component & \\
SS-QOL & $179(163 / 199)$ \\
\hline
\end{tabular}

HSp: handgrip strength of the paretic limb; HSnp: handgrip strength of the non-paretic limb; GS: Gait speed; TUGT: Timed "Up and Go" test; SS-QOL: Stroke Specific Quality of Life. Data are expressed as mean \pm SD for parametric variables, and as median and interquartile range $(25 \%$ and $75 \%)$ for nonparametric variables.

to activities of daily living, it is fundamentally important to evaluate functionality following the conceptual framework of the ICF, which allows a biopsychosocial view in which the health condition is identified along with other factors that can have a negative or positive impact ${ }^{7)}$. Thus, the present study aimed to identify ICF categories in assessment tools commonly used in the rehabilitation of stroke survivors and characterize the functionality of these individuals using the ICF evaluation model.

The assessment tools employed for a functional evaluation of the volunteers in this study addressed 63 ICF categories: 24 related to body functions and structures; 36 related to activity and participation; and 3 related to environmental factors (Table 3). Comparing these categories to the core set for stroke, the assessment tools employed in the present study addressed $37.5 \%$ of the categories of the "body functions and structures" component, $47.2 \%$ of the categories of the "activity and participation" component, and $6 \%$ of the categories of the "environmental factors" component. However, one should bear in mind that the categories of the core set are limited to the evaluation of only the second level of the ICF, whereas the categories indicated by the assessment tools employed in the present study consider all the hierarchical levels of the ICF.

Among the 24 categories related to the "body functions and structures" component, some were congruent with the clinical practice of physical therapists, such as "muscle power functions (b730)"; "power of muscles of one side of the body (b7302)"; "involuntary movement reaction functions (b755)" and "vestibular function of balance (b2351)", whereas others were incongruent with physical therapy, such as "global psychosocial functions (b122)"; "mental functions of language (b167)"; and "emotional functions (b152)". This allows evaluating an individual with regard to diverse aspects of body functions and underscores the importance of interdisciplinary therapy for adequate functional rehabilitation.

Although some researchers recommend evaluating activity and participation separately ${ }^{5,11,12)}$, there is no differentia- 
Table 3. Identification of ICF categories assessed by the primary outcomes of the instruments

\begin{tabular}{ll}
\hline Body Function & b122 Global psychosocial functions \\
& b126 Personality \\
& b1263 Psychic stability \\
& b1264 Openness to experience \\
& b1265 Optimism \\
& b1266 Confidence \\
& b1300 Energy level \\
& b1302 Appetite \\
& b1400 Sustaining attention \\
& b144 Memory functions \\
& b152 Emotional functions \\
b167 Mental functions of language & b1672 Language functions \\
b2100 Visual acuity functions \\
b2101Visual field functions \\
b2102 Quality of vision \\
b2351 Vestibular function of balance \\
b320 Articulation functions \\
b330 Fluency and rhythm of speech functions \\
b455 Exercise tolerance functions \\
b510 Ingestion functions \\
b730 Muscle power functions \\
b7300 Power of isolated muscles and muscle \\
groups \\
b7302 Power of muscles of one side of the \\
body \\
b755 Involuntary movement reaction functions
\end{tabular}

tion of these components in the ICF, as both are presented on a single codification list ${ }^{7}$. This is most likely the reason for a greater number of categories related to the "activity and participation" component. Thus, categories that represent the capacity to perform daily activities, such as "walking" (d450), "doing housework" (d640) and "eating" (d550), as well as categories that represent the actual performance of an individual in the social context, such as "assisting others" (d660), "informal social relationships" (d750), "family relationships" (d760), and "remunerative employment" (d850) can be identified. The identification of these categories allows the rehabilitation process to be directed toward more specific objectives focused on the patient's expectations, thereby contributing to a greater degree of humanization and treatment effectiveness ${ }^{30)}$.

Concerning environmental factors, important categories
Table 3. Continued

\begin{tabular}{ll}
\hline d360 Using communication devices and \\
techniques \\
d3600 Using communication devices \\
d4 Mobility \\
d410 Changing basic body position \\
d4103 Sitting \\
d4104 Standing \\
d4105 Bending \\
d4106 Shifting the body's center of gravity \\
d4154 Maintaining a standing position \\
d440 Fine hand use \\
d445 Hand and arm use \\
d4453 Turning or twisting the hands or arms \\
d450 Walking \\
d4500 Walking short distances \\
d4551 Climbing \\
d465 Moving around using equipment \\
d5101 Washing whole body \\
d530 Toileting \\
d540 Dressing \\
d550 Eating \\
d6300 Preparing simple meals \\
d640 Doing housework \\
d660 Assisting others \\
d750 Informal social relationships \\
d760 Family relationships \\
d7702 Sexual relationships \\
d850 Remunerative employment \\
d920 Recreation and leisure \\
indoor and outdoor mobility and transportation \\
e125 Products and technology for communi- \\
cation \\
e410 Individual attitudes of immediate family \\
members
\end{tabular}

b: body function; d: activity and participation; e: environmental factors

were addressed in the assessment tools employed in the present study, such as "products and technology for personal indoor and outdoor mobility and transportation" (e120), "products and technology for communication" (e125), and "individual attitudes of immediate family members" (e410). These categories are important, as they allow the identification of facilitators of or barriers to the functional rehabilitation process ${ }^{7}$.

The use of the ICF model allows healthcare professionals to consider a specific functional profile for each patient ${ }^{7)}$, allowing the identification of capacities and limitations on the 3 levels that involve health ${ }^{7)}$ as well as the development of a treatment plan centered on the patient and his/her specific process of functionality and disability ${ }^{29)}$. For the ICF theoretical model to be used in clinical practice, it is necessary for the measurement instruments employed to be validated 
and their concepts to be associated with the ICF components and categories. Thus, grip strength was used as the outcome for the evaluation of the "body functions and structures" component, as this measure has proven to be an indicator of overall strength and functional capacity ${ }^{14)}$. Natural and maximum gait speed and functional mobility were used to evaluate the activity component, as these measures are used to characterize the functional level of individuals with hemiparesis and reflect physiological and functional changes ${ }^{15)}$.

In the present study, the volunteers had diminished grip strength on the affected half of the body and deficient functional mobility, as the mean time on the TUGT was $16 \mathrm{sec}-$ onds, and more than 14 seconds is indicative of a greater risk of falls ${ }^{22)}$. However, as functional gait speed should be equal to or faster than $1 \mathrm{~m} / \mathrm{s}^{31)}$, the volunteers in the present study did not exhibit compromised gait speed, as mean natural and maximum gait speed was $1 \mathrm{~m} / \mathrm{s}$ and $1.3 \mathrm{~m} / \mathrm{s}$, respectively.

The total SS-QOL score was used as an indication of participation. In general, a positive tendency was found regarding the evaluation of $H R Q 0 L$ and participation among the volunteers. This finding may be related to the fact that the sample was composed of individuals in the chronic phase of a stroke, as a longer time after a stroke favors the patient's ability to cope with his/her limitations, which seems to have a positive effect on $\mathrm{HRQoL}^{32,33)}$. From the clinical standpoint, participation is a frequent goal of therapy, as it allows the individual to construct relationships and develop skills to meet social expectations, which can lead to finding purpose and meaning in life, positively impacting the physical and mental health of individuals with hemiparesis. Thus, restoring the patient's ability to perform paid work (d850) and participate in recreation and leisure activities (d920) are important aspects to consider in the rehabilitation process following a stroke.

The present study has limitations that should be addressed. The first is regarding the divergence in the results of studies that employed the same methodology to determine associations between assessment tools and ICF categories. Each study used a different category level to investigate such associations; Teixeira-Salmela et al. ${ }^{25)}$ classified the items of each assessment tool up to the third hierarchical level of the ICF, whereas Geyh et al. ${ }^{17)}$, Faria et al. ${ }^{18)}$, and Schepers et al. ${ }^{26)}$ limited their studies to the second level. Thus, when categories on different hierarchical levels of the ICF were cited for the same concept, the categories that represented the highest detailing level of the concept evaluated (highest hierarchical level of the ICF) were chosen. Another limitation is regarding the failure to include a specific assessment tool to evaluate the "environmental factors" domain. Despite these limitations, the present results are important for the field of physical therapy and rehabilitation, as the information offered provides a greater understanding of the ICF conceptual model and describes the functionality of individuals with hemiparesis, as recommended by the World Health Organization.

In conclusion, the assessment tools employed in the present study are widely used in physical therapy and address 63 categories of the ICF, which allows a broader evaluation of patients with hemiparesis stemming from a stroke by considering different aspects of functionality. Thus, the use of the
ICF can be more easily incorporated into clinical practice, allowing a more complete view of circumstances that either favor or hinder the rehabilitation process following a stroke. Healthcare professionals can therefore record the disabilities and disadvantages that the patient faces in society, the impact on activities of daily living, movement limitations, body structures affected, degree of activity and social participation, environmental phenomena involved, as well as the need for intervention and technological assistance.

\section{ACKNOWLEDGEMENT}

Funding for this study was provided by the Brazilian fostering agency the State of São Paulo Research Foundation (FAPESP) under process number 2013/10877-7.

\section{REFERENCES}

1) Mackay J, Mensah GA: The Atlas of Heart Disease and Stroke. Geneva: World Health Organization, 2002.

2) Chong JY, Sacco RL: Epidemiology of stroke in young adults: race/ethnic differences. J Thromb Thrombolysis, 2005, 20: 77-83. [Medline] [CrossRef]

3) Go AS, Mozaffarian D, Roger VL, et al. American Heart Association Statistics Committee and Stroke Statistics Subcommittee: heart disease and stroke statistics - 2013 update: a report from the American Heart Association. Circulation, 2013, 127: 6-245. [CrossRef]

4) Murray CJ, Vos T, Lozano R, et al.: Disability-adjusted life years (DALYs) for 291 diseases and injuries in 21 regions, 1990-2010: a systematic analysis for the Global Burden of Disease Study 2010. Lancet, 2012, 380: 21972223. [Medline] [CrossRef]

5) Barak S, Duncan PW: Issues in selecting outcome measures to assess functional recovery after stroke. NeuroRx, 2006, 3: 505-524. [Medline] [CrossRef]

6) Tempest S, McIntyre A: Using the ICF to clarify team roles and demonstrate clinical reasoning in stroke rehabilitation. Disabil Rehabil, 2006, 28 : 663-667. [Medline] [CrossRef]

7) World Health Organization: International Classification of Functioning, Disability and Health. Geneva: World Health Organization, 2001.

8) Geyh S, Kurt T, Brockow T, et al.: Identifying the concepts contained in outcome measures of clinical trials on stroke using the International Classification of Functioning, Disability and Health as a reference. J Rehabil Med, 2004, 44: 56-62. [Medline] [CrossRef]

9) Thonnard JL, Penta M: Functional assessment in physiotherapy. A literature review. Eura Medicophys, 2007, 43: 525-541. [Medline]

10) Bertolucci PH, Brucki SM, Campacci SR, et al.: O Mini-Exame do Estado Mental em uma população geral. Impacto da escolaridade. Arq Neuropsiquiatr, 1994, 52: 1-7. [Medline] [CrossRef]

11) Salter K, Jutai JW, Teasell R, et al.: Issues for selection of outcome measures in stroke rehabilitation: ICF Participation. Disabil Rehabil, 2005, 27: 507-528. [Medline] [CrossRef]

12) Salter K, Jutai JW, Teasell R, et al.: Issues for selection of outcome measures in stroke rehabilitation: ICF activity. Disabil Rehabil, 2005, 27: $315-$ 340. [Medline] [CrossRef]

13) Salter K, Jutai JW, Teasell R, et al.: Issues for selection of outcome measures in stroke rehabilitation: ICF Body Functions. Disabil Rehabil, 2005, 27: 191-207. [Medline] [CrossRef]

14) Curb JD, Ceria-Ulep CD, Rodriguez BL, et al.: Performance-based measures of physical function for high-function populations. J Am Geriatr Soc, 2006, 54: 737-742. [Medline] [CrossRef]

15) Flansbjer UB, Holmbäck AM, Downham D, et al.: Reliability of gait performance tests in men and women with hemiparesis after stroke. J Rehabil Med, 2005, 37: 75-82. [Medline] [CrossRef]

16) Salbach NM, Mayo NE, Higgins J, et al.: Responsiveness and predictability of gait speed and other disability measures in acute stroke. Arch Phys Med Rehabil, 2001, 82: 1204-1212. [Medline] [CrossRef]

17) Geyh S, Cieza A, Kollerits B, et al.: Content comparison of health-related quality of life measures used in stroke based on the international classification of functioning, disability and health (ICF): a systematic review. Qual Life Res, 2007, 16: 833-851. [Medline] [CrossRef]

18) Faria CD, Silva SM, Corrêa JC, et al.: Identificação das categorias de par- 
ticipação da CIF em instrumentos de qualidade de vida utilizados em indivíduos acometidos pelo acidente vascular encefálico. Rev Panam Salud Publica, 2012, 31: 338-344. [Medline]

19) Figueiredo I, Sampaio RF, Mancini MC, et al.: Teste de força de preensão utilizando o dinamômetro Jamar. Acta Fisiatr, 2007, 14: 104-110.

20) Mercier C, Bourbonnais D: Relative shoulder flexor and handgrip strength is related to upper limb function after stroke. Clin Rehabil, 2004, 18: 215221. [Medline] [CrossRef]

21) Podsiadlo D, Richardson S: The timed "Up \& Go": a test of basic functional mobility for frail elderly persons. J Am Geriatr Soc, 1991, 39: 142-148. [Medline]

22) Flansbjer UB, Downham D, Lexell J: Knee muscle strength, gait performance, and perceived participation after stroke. Arch Phys Med Rehabil, 2006, 87: 974-980. [Medline] [CrossRef]

23) Silva SM, Corrêa FI, Faria CD, et al.: Psychometric properties of the stroke specific quality of life scale for the assessment of participation in stroke survivors using the rasch model: a preliminary study. J Phys Ther Sci, 2015, 27: 389-392. [Medline] [CrossRef]

24) Silva SM, Corrêa FI, Faria CD, et al.: Comparison of quality-of-life instruments for assessing the participation after stroke based on the Internationa Classification of Functioning, Disability and Health (ICF). Braz J Phys Ther, 2013, 17: 470-478. [Medline] [CrossRef]

25) Teixeira-Salmela LF, Magalhães LC, Souza AC, et al.: Adaptação do Perfi de Saúde de Nottingham: um instrumento simples de avaliação da qualidade de vida. Cad Saude Publica, 2004, 20: 905-914. [Medline] [CrossRef]
26) Stucki G, Cieza A, Ewert T, et al.: Application of the International Classification of Functioning, Disability and Health (ICF) in clinical practice. Disabil Rehabil, 2002, 24: 281-282. [Medline] [CrossRef]

27) Cieza A, Geyh S, Chatterji S, et al.: ICF linking rules: an update based on lessons learned. J Rehabil Med, 2005, 37: 212-218. [Medline] [CrossRef]

28) Teixeira-Salmela LF, Neto MG, Magalhães LC, et al.: Content comparisons of stroke-specific quality of life based upon the international classification of functioning, disability, and health. Qual Life Res, 2009, 18: 765-773. [Medline] [CrossRef]

29) Schepers VP, Ketelaar M, van de Port IG, et al.: Comparing contents of functional outcome measures in stroke rehabilitation using the International Classification of Functioning, Disability and Health. Disabil Rehabil, 2007, 29: 221-230. [Medline] [CrossRef]

30) Steiner WA, Ryser L, Huber E, et al.: Use of the ICF model as a clinical problem-solving tool in physical therapy and rehabilitation medicine. Phys Ther, 2002, 82: 1098-1107. [Medline]

31) Olney SJ, Richards C: Hemiparetic gait following stroke. Part I: Characteristics. Gait \& Posture, Oxford, 1996, 136-148.

32) Kim K, Kim YM, Kim EK: Correlation between the activities of daily living of stroke patients in a community setting and their quality of life. J Phys Ther Sci, 2014, 26: 417-419. [Medline] [CrossRef]

33) Shim S, Kim H, Jung J: Comparison of upper extremity motor recovery of stroke patients with actual physical activity in their daily lives measured with accelerometers. J Phys Ther Sci, 2014, 26: 1009-1011. [Medline] [CrossRef] 